\title{
Epidemiology of Traumatic Spinal Injury: A 15-Year Retrospective Study of 1092 Cases
}

\author{
Sane JC ${ }^{1}$, Hope $\mathrm{JMV}^{2}$, Souleymane $\mathrm{D}^{3}$, Kassé $\mathrm{AN}^{3}$, Diouf $\mathrm{JD}^{3}$, Nikiema $\mathrm{AN}^{3}$, Thiam $\mathrm{B}^{3}$, Diallo $\mathrm{MB}^{3}$, Camara EHS ${ }^{3}$ and Habib Sy $\mathrm{M}^{3}$
}

${ }^{1}$ Gaston Berger University of Saint Louis, Senegal

${ }^{2}$ Department of Orthopedics and Trauma Surgery, Fellow West African College of Surgeons (FWACS), Rwanda Military Hospital (RMH), University of Rwanda, Est Africa, Kigali, Rwanda

${ }^{3}$ Orthopedics and Trauma Surgery Department, Cheikh Anta Diop University of Dakar, Grand-Yoff General Hospital, Senegal

\begin{abstract}
Background: Spinal trauma is a well-documented problem in developed countries but literature has been mute on this problem in developing counties. The purpose of this study was to elucidate epidemiological characteristics of spine
\end{abstract} trauma in our center over a 15-year period.

Methods: All consecutive patients with acute spinal trauma who were admitted in our center from March 2003 to March 2018 were included. The analysis was focused on patient-related demographic characteristics, cause and mechanism of injury, level and type of injury, neurological deficit, associated injuries, management and outcome. All of the statistical calculations were performed using the Statistical Package for Social Sciences (SPSS). Statistical analyses were conducted using the Student t-test and nonparametric tests (Mann-Whitney U-test, Kruskal-Wallis test). Values for $p<0.05$ were regarded as statistically significant and all confidence intervals were expressed at $95 \%$.

Results: A total of 1,092 patients with acute traumatic spinal injuries were managed in our trauma center. There were $74.3 \%$ males and $25.7 \%$ females with mean age 34.5 years. Young adults (age group: 18-39 years) were more affected with $58.9 \%$. The leading mechanism of injury was compression with $39.2 \%$. The most common cause of accident was motor vehicle collision accident $(58.5 \%)$ followed by high-energy falls $(32.6 \%)$. Six hundred eighty-seven patients $(62.8 \%)$ had spinal cord injury, with $14.4 \%$ complete tetraplegia and $7.7 \%$ complete paraplegia. Overall, the use of operative treatment $(64.8 \%)$ exceeded that of conservative treatment $(35.2 \%)$.

Conclusion: This study's unique feature of delineating variables with statistical significance trending toward better management provides useful data to guide future researches, benchmarking, public health policy, and efficient resource allocation for the management of spine trauma.

Keywords: Epidemiology; Spine trauma; Developing countries

\section{Introduction}

Traumatic spinal injury (TSI) is a serious debilitating injury that exerts a devastating effect on an individual from a physical, psychological, and socioeconomic point of view, and places an immense burden on society from a public health perspective [1-4]. The estimated lifetime cost of treating a 25 -year-old patient with a spinal cord injury (SCI) can reach 2.8 million US dollars [5-7]. The incidence of spinal trauma is region-specific due to unique geographic and demographic characteristics $[8,9]$. Worldwide incidence of spinal injury with or without cord damage is $12.1-57.8$ cases per million per year [10,11]. Knowledge of current epidemiology of spine trauma trends assists in health care planning, fine-tuning of primary prevention methods, optimization of management and benchmarking purposes $[12,13]$. But now, only data from developed countries have been thorough undertaken [14-16]. The main purpose of this study was to elucidate epidemiological characteristics of spine trauma in our center over a 15year period.

\section{ORCID ID: 0000-0003-1127-0586}

\section{Materials and Methods}

All patients with acute TSI with or without SCI who were admitted in our center from March 2003 to March 2018 were retrospectively selected from trauma registry for all ages and all spinal injuries. Patients presenting minor injuries (isolated spinous process fractures), paravertebral soft tissue injury (muscular sprains) and injuries to the lumbar transverse processes attributable to the mechanism of avulsion lesion secondary to a pelvic injury were excluded. Patients with congenital, metabolic, rheumatologic diseases and neoplasms such as Klippel-Feil syndrome, osteoporosis, ankylosing spondylitis, and multiple myeloma were also excluded.

The analysis was focused on patient-related demographic characteristics, cause and mechanism of injury, level and type of injury, neurological deficit, associated injuries (AI), management and outcome. Based on the notion of dominant lesional vector force and increasing severity of trauma, three different mechanisms of injury were used to distinguish between three types of injuries with compression: Type A injury, distraction in either flexion or extension: Type B injury and rotation: Type $\mathrm{C}$ injury.

For the localization of spinal injuries, the spinal column was divided into 5 different segments according to anatomic and physiologic differences in each spinal segment, with upper cervical: occipital condyle (C0), atlas (C1) and axis (C2); lower cervical (C3-C7), thoracic (T1-T12), lumbar (L1-L5) and sacrococcygeal (SC) segments (Tables 1-4). Any patient sustaining an injury at more than one of the aforementioned segments was classified as having multi-segmental

*Corresponding author: Jean Marie Vianney Hope, Department of Orthopedics and Trauma Surgery, Fellow West African College of Surgeons (FWACS), Rwanda Military Hospital (RMH), University of Rwanda, Est Africa, Kigali, Rwanda, Tel: +250789364492; E-mail: hopejmv@gmail.com

Received December 06, 2018; Accepted December 26, 2018; Published December 31, 2018

Citation: Sane JC, Hope JMV, Souleymane D, Kassé AN, Diouf JD, et al. (2018) Epidemiology of Traumatic Spinal Injury: A 15-Year Retrospective Study of 1092 Cases. J Spine 7: 429. doi: 10.4172/2165-7939.1000429

Copyright: ( 92018 Sane JC, et al. This is an open-access article distributed under the terms of the Creative Commons Attribution License, which permits unrestricted use, distribution, and reproduction in any medium, provided the original author and source are credited. 


\begin{tabular}{|c|c|c|c|}
\hline Neurological status & Admission & Discharge & Mean follow-up \\
\hline ASIA grade A & $241(22.1 \%)$ & $179(16.4 \%)$ & $117(10.7 \%)$ \\
\hline ASIA grade B & $119(10.8 \%)$ & $116(10.6 \%)$ & $37(3.1 \%)$ \\
\hline ASIA grade C & $157(14.3 \%)$ & $152(13.9 \%)$ & $170(15.5 \%)$ \\
\hline ASIA grade D & $170(15.6 \%)$ & $179(16.4 \%)$ & $219(20.1 \%)$ \\
\hline ASIA grade E & $405(37.2 \%)$ & $429(39.3 \%)$ & $442(40.4 \%)$ \\
\hline Death & $0(0 \%)$ & $37(3.4 \%)$ & $48(5.1 \%)$ \\
\hline Total & $1092(100 \%)$ & $1092(100 \%)$ & $109 \%)$ \\
\hline
\end{tabular}

Table 1: Neurological evolution of spinal cord injured patients according to the American Spinal Injury Association (ASIA) grading system.

\begin{tabular}{|c|c|c|}
\hline Variable & Al (n=523) & p-Value \\
\hline Age & 32.4 & 37.9 \\
\hline Gender (M : F) & $434: 89$ & $378: 191$ \\
\hline Injury localization (UC : LC : T: L: SC: MS) & $51: 107: 113: 156: 30: 66$ & $67: 33633: 91: 13: 29$ \\
\hline Injury type (A: B : C) & $88: 189: 246$ & $340: 105: 124$ \\
\hline Number of injured levels (SL : MLC: MLNC) & $441: 47: 50$ & 0.13 \\
\hline Neurologic deficit (Present: Absent) & $161: 362$ & 0.0012 \\
\hline
\end{tabular}

M: Male; F: Female; UC: Upper Cervical; LC: Lower Cervical; T: Thoracic; L: Lumbar; SC: Sacrococcygeal; MS: Multisegmental; SL: Single Level; MLC: Multilevel Contiguous; MLNC: Multilevel Noncontiguous

Table 2: Univariate analysis of variance (ANOVA) comparing patients who suffered from Associated Injuries (Al) with those who did not.

\begin{tabular}{|c|c|c|}
\hline Variable & Odds ratio & 95\% confidence interval \\
\hline Neurological deficit & 1.2795 & $1.0009-2.1146$ \\
\hline Male & 1.7 & $1.0067-2.009$ \\
\hline Type C injury & 2.0045 & $1.0295-3.0397$ \\
\hline Thoracolumbar junction injury & 6.0214 & $1.0461-3.0172$ \\
\hline Multisegmental injury & 7.0102 & $3.0995-8.0728$ \\
\hline Traffic accident & 7.5 & $4.0998-9.0959$ \\
\hline High-energy fall & 8.4132 & $3.2077-8.1708$ \\
\hline
\end{tabular}

Table 3: Factors that significantly increase the incidence of associated injuries.

injuries. For the level of injuries, we have classified spinal injuries into single level (SL) which are injuries to one vertebra and/or one intervertebral disc and multilevel injuries (injury at more than one level of the vertebral column). The later were further classified as multilevel contiguous (MLC) when $\geq 2$ adjacent vertebrae were involved and multilevel noncontiguous (MLNC) if there was preservation of at least one uninjured vertebra between the injuries.

For the type of injuries (Table 4), based on diagnostic imaging studies including conventional radiographs, Computed Tomography (CT) and Magnetic Resonance Imaging (MRI), upper cervical spine injuries were classified into occipital condyle fracture, Jefferson fracture (or burst fracture of $\mathrm{C} 1$ : When there are both anterior and posterior arch fractures), odontoid type 2 (fracture through the base of the dens), odontoid type 1 (oblique fracture through the odontoid tip), odontoid type 3 (fracture through the body of C2), C2 Hangman's fracture (fracture of both pedicles or pars interarticularis of $\mathrm{C} 2$ ), C1-2 dislocations, C1-2 miscellaneous fractures (affecting the C1-C2 lamina, body, lateral mass, or spinous process). The modified Argenson classification [17] was used for lower cervical spine injuries, whereas Magerl classification [18] has been used for thoracic and lumbar spine injuries (Table 4).

The American Spinal Injury Association (ASIA) grading system was used to document SCI with ASIA A: Complete; B-D: Incomplete and E: Normal. Two types of SCI without radiological abnormalities (SCIWORA) were differentiated. The SCIWORA type 1 was positive neurologic findings and negative plain $\mathrm{x}$-ray and CT scan but pathologic spinal cord MRI. The second type was defined as abnormal neurologic examination with normal imaging (including MRI). Any improvement or deterioration in spinal injury grade during treatment and follow-up was documented. All the cases of death were recorded.

All of the statistical calculations were performed using the Statistical Package for Social Sciences (SPSS) for macOS version 24.0 (SPSS Inc. Chicago, Illinois, US). Values for $\mathrm{p}<0.05$ were regarded as statistically significant and all confidence intervals (CI) were expressed at $95 \%$. Descriptive statistics were presented as number of cases, percentage and mean. Statistical analyses were conducted using the Student t-test and nonparametric tests including the Mann-Whitney U-test and the Kruskal-Wallis test. The Pearson's Chi-square $\left(\chi^{2}\right)$ testing of frequency data was performed where appropriate. Analysis of variance (ANOVA), odd ratio (OR) of associated injuries (AI) was calculated using forward stepwise regressions.

\section{Results}

During the 15-year period, a total of 1,092 patients with acute TSI were managed in our trauma center. They represented $4.3 \%$ of patients admitted due to traumas (a total of 25,396 patients) in the same period. The average number of spinal trauma patients per year and per month is respectively 73 and 6 . The cohort comprised $812(74.3 \%)$ males and $280(25.7 \%)$ females. The male-to-female ratio was $2.9: 1$. The mean age of the study population was 34.5 years (range, 11 months- 89 years). Young adults (age group of 18-39 years) were more affected with $58.9 \%$. The typical patient was a male in the third decade. Distribution of different age group and gender, according to the World Health Organization (WHO) age group classification is presented in Figure 1.

The leading mechanism of injury was compression (type A injury) in $39.2 \%$, followed by rotation (type C injury) in $33.9 \%$ and 
Citation: Sane JC, Hope JMV, Souleymane D, Kassé AN, Diouf JD, et al. (2018) Epidemiology of Traumatic Spinal Injury: A 15-Year Retrospective Study of 1092 Cases. J Spine 7: 429. doi: 10.4172/2165-7939.1000429

Page 3 of 7

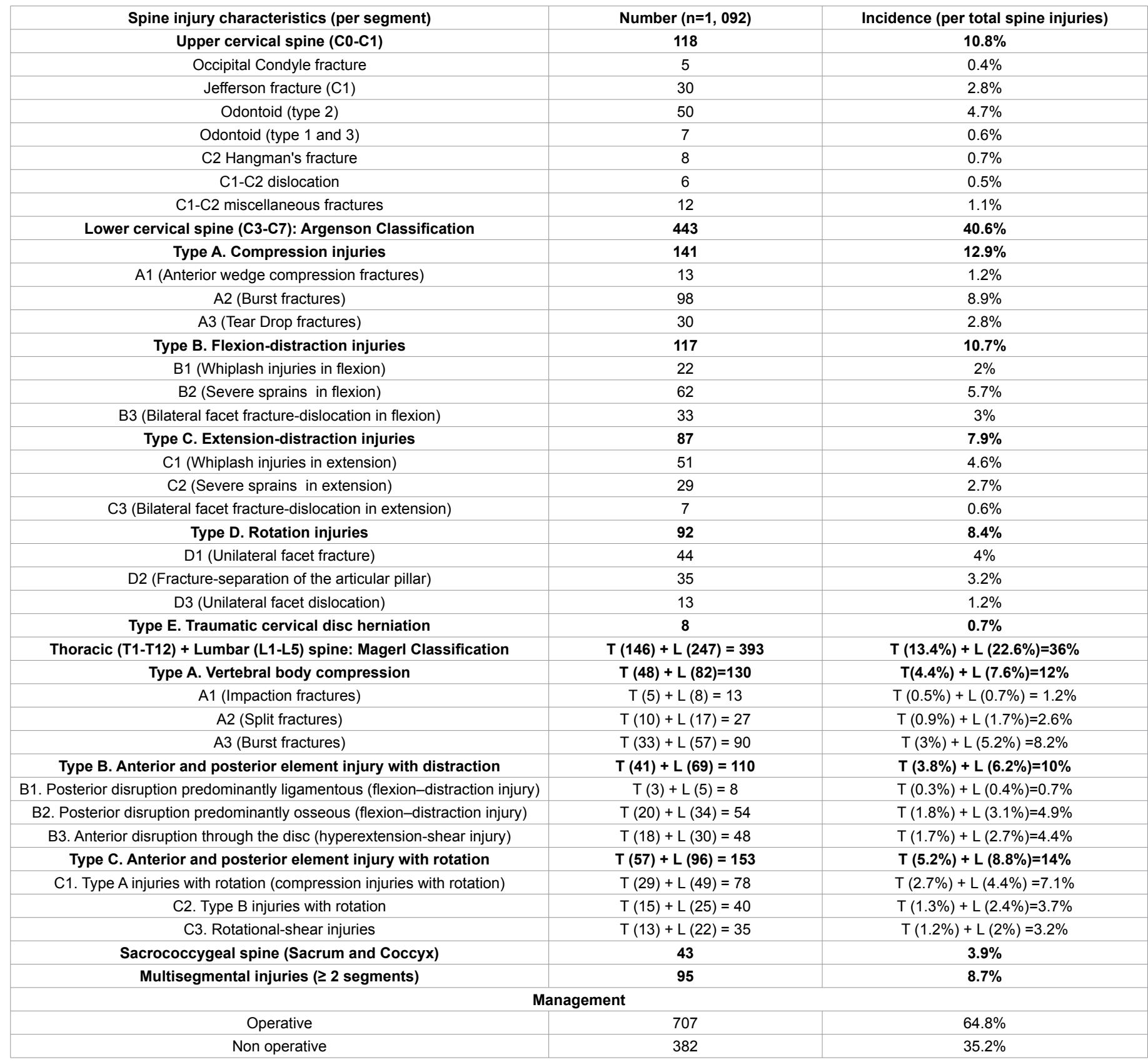

Table 4: Spinal injury characteristics of 1092 trauma patients with spinal injuries.

distraction (type B injury) in $26.9 \%$. Our results revealed that specific spinal segments were more prone to certain injury mechanisms. For instance, the majority of compression injuries were found in lumbar spine, whereas injuries caused by a distraction mechanism more frequently occurred in the lower cervical spine. The rotational injuries were predominantly found in the mobile segments of the spine (lower cervical spine and thoracolumbar junction) as shown in Figure 2.

The most common cause of accident was traffic collision, also called motor vehicle collision accident (MVC, 58.5\%) with 244 (22.3\%) car accidents, 291 (26.6\%) motorcycle accidents, 43 (4\%) motor vehicle versus pedestrian accidents, 32 (3\%) bicycle accidents and $29(2.7 \%)$ wagon accident. Of the cases involving MVC, $92 \%$ were unrestrained at the time of the accident. The high-energy fall, which was defined as a fall from at least $2 \mathrm{~m}$ was responsible of spinal injuries in $32.6 \%$.
High-energy fall-related injuries included deep falls in $23(2.1 \%)$, high building falls in 86 (7.8\%), falls from trees in $84(7.6 \%)$, electric pole falls in $31(2.8 \%)$, accidental domestic falls $104(9.6 \%)$ and falls from attempted suicide by defenestration in $21(2 \%)$. Simple falls were responsible of spinal injuries in 8 patients $(0.7 \%)$. Eighteen patients (1.7\%) sustained a spinal injury as a result of a sport-related activity. A blunt, direct impact to the spine caused spinal injuries in $70(6.4 \%)$ cases. In the remaining $8(0.8 \%)$ patients the causes were gunshot injuries in 6 patients $(0.6 \%)$ and railway accident in 2 patients $(0.2 \%)$.

The analyses of correlation between the cause of accident and the resulting spinal injury type revealed that type A injuries were predominantly caused by falls (high-energy and simple falls), while type B injuries resulted from high-energy trauma including MVC and falls from great height. MVC were the leading cause of type $\mathrm{C}$ 
Citation: Sane JC, Hope JMV, Souleymane D, Kassé AN, Diouf JD, et al. (2018) Epidemiology of Traumatic Spinal Injury: A 15-Year Retrospective Study of 1092 Cases. J Spine 7: 429. doi: 10.4172/2165-7939.1000429

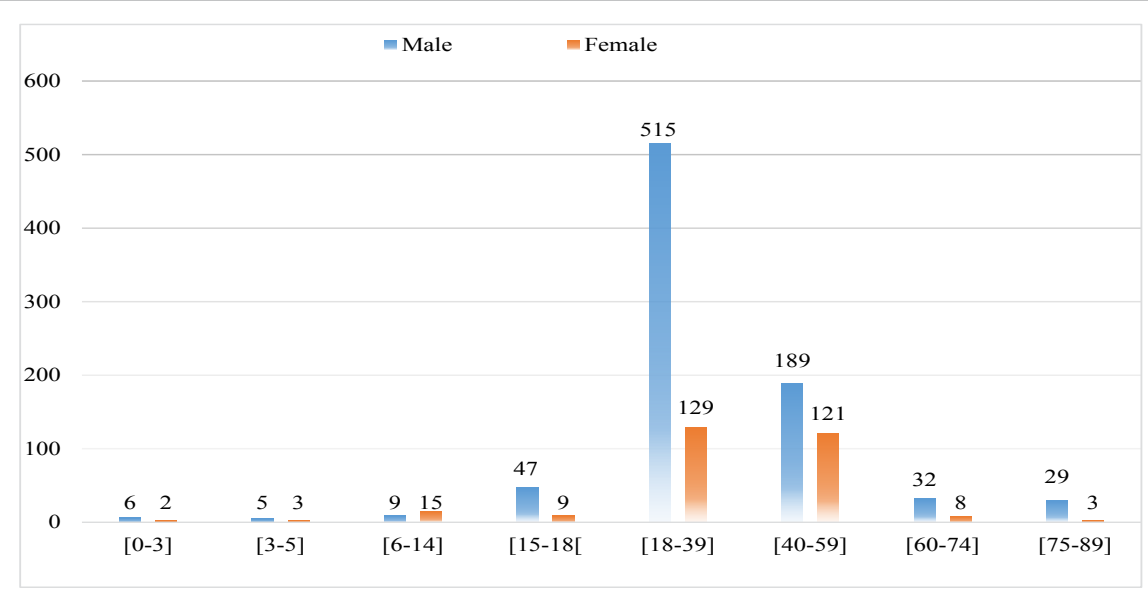

Figure 1: Age distribution of complete study population highlighting that the majority of patients sustained the spinal injuries between 18 and 59 years of age and the rarity of spinal column trauma in pediatric population (under 15 years of age).

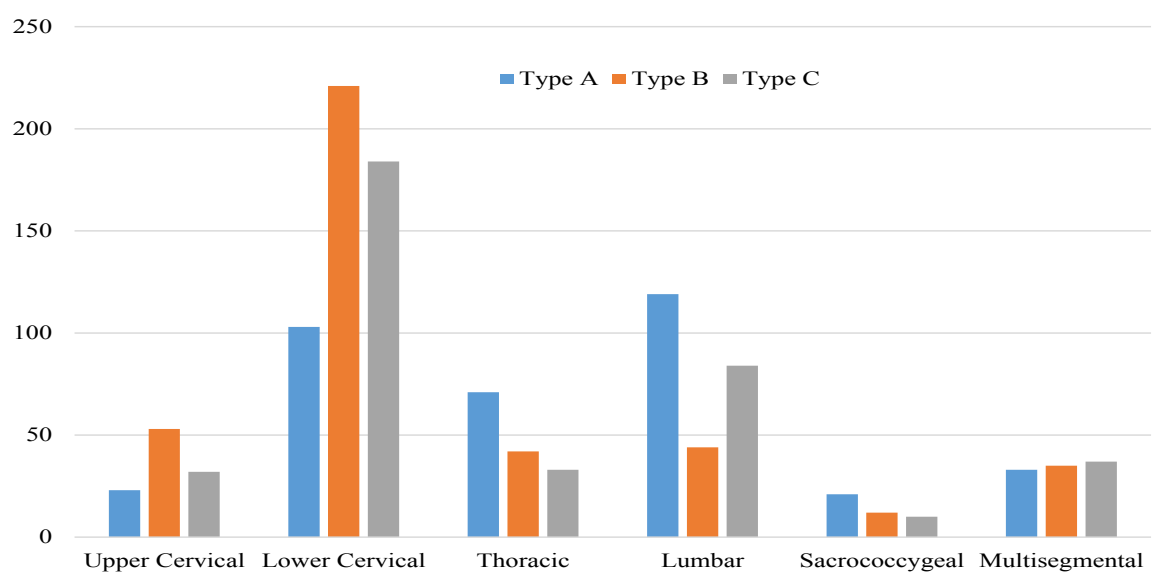

Figure 2: Incidence of injury mechanism in each spinal segment revealing that specific spinal segments were more prone to certain injury mechanisms with the majority of compression (type A), distraction (type B) and rotational (type C) injuries found respectively in lumbar spine, lower cervical spine and the mobile segments of the spine.

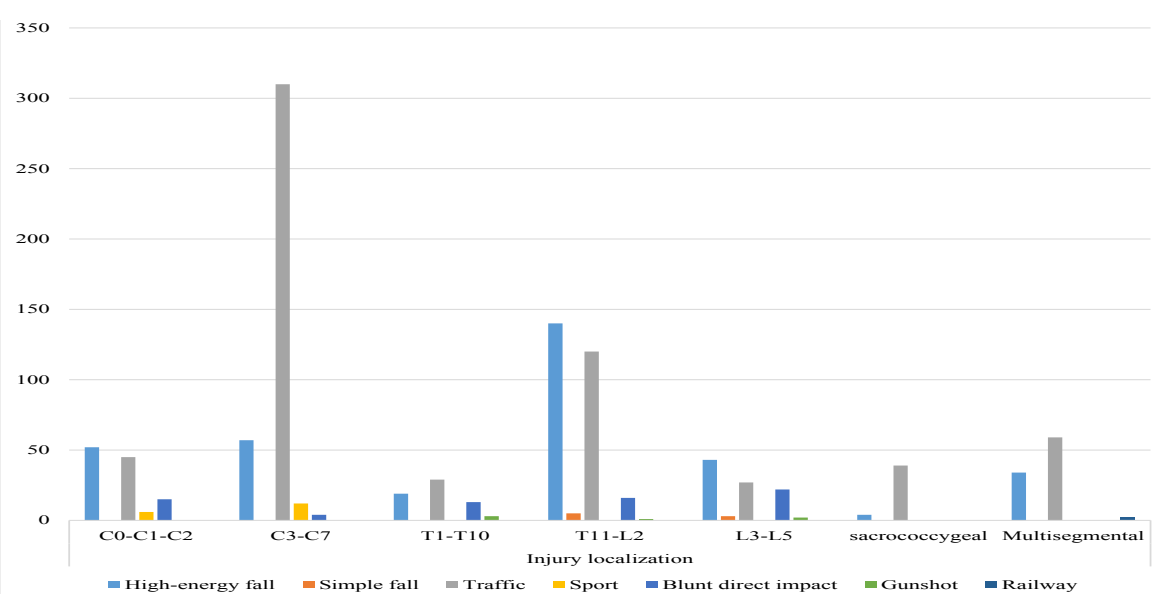

Figure 3: Correlation of cause of accident and injury localization showing that fall-related injuries occurred predominantly at the thoracolumbar junction (T11-L2) while patients involved in either traffic or sport accidents exhibited a significant increase in lower cervical spinal injuries.

injuries. Investigating the correlation between the cause of accident and the injury localization, our data Figure 3 showed that fall-related injuries (high-energy and simple falls) occurred predominantly at the thoracolumbar junction (T11-L2). However, patients that sustained MVC exhibited a significant increase in lower cervical spinal injuries $(\mathrm{p}=0.001)$. Furthermore, sports-related injuries occurred more often at 


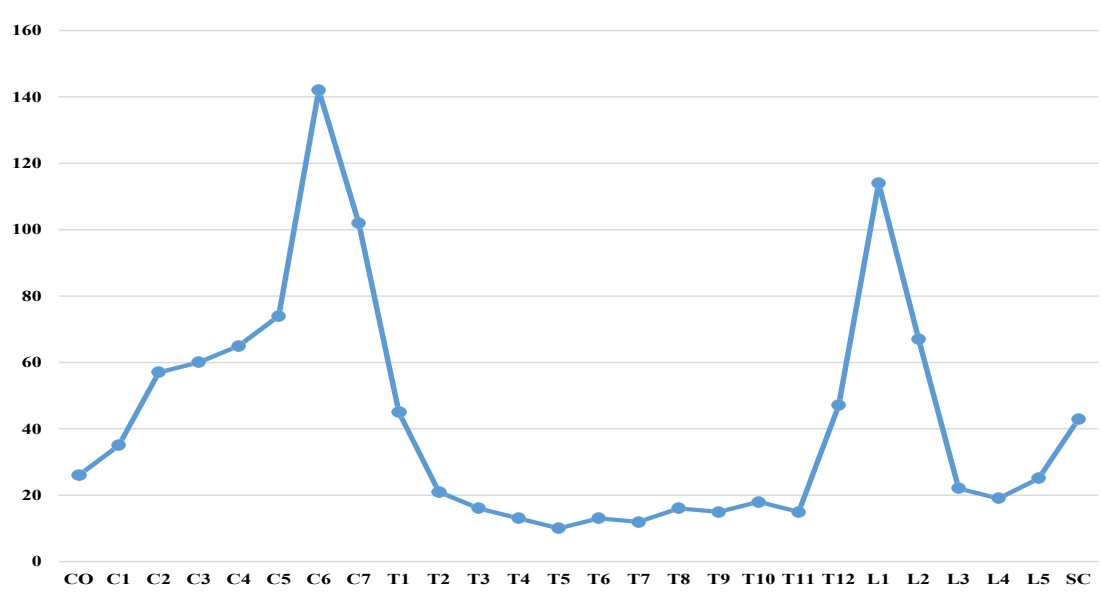

Figure 4: Distribution of spinal injuries for each vertebra showing that the most frequently injured vertebra was the sixth cervical vertebra followed by the first lumbar vertebra. The distribution mirrored the curve with two major peaks; one at the lower cervical level and the other at thoracolumbar level.

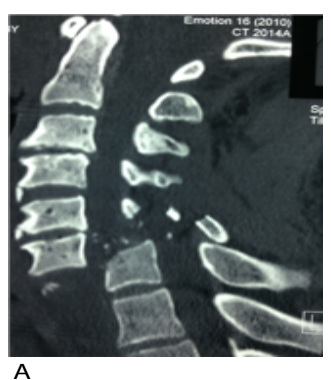

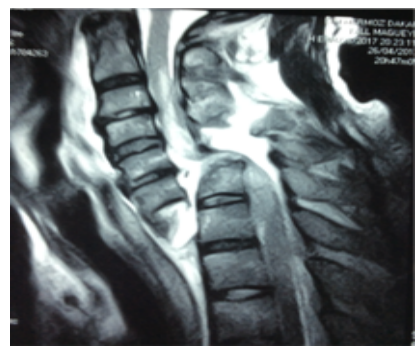

B

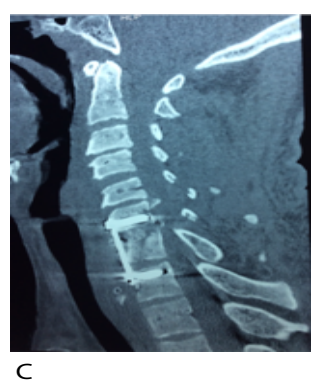

C

Figure 5: (A) Preoperative cervical CT scan of a 52-year-old driver, who sustained during a traffic collision a lower cervical spine trauma, showing fracture dislocation of C6-C7 with overlapping of C7 at the C5 level. (B) Sagittal T2-weighed MRI scan revealing severe spinal cord contusion and expansion of fractures into the spinal canal at the levels of C5-C6-C7 vertebrae. (C) Immediate postoperative CT scan, after reduction, hemicorporectomy of C7, discectomy C6-C7, interbody fusion with iliac crest bone graft and anterior fixation with cervical plate, showing restoration of spinal column alignment.

the lower cervical spine $(\mathrm{p}=0.003)$. The incidence of injuries due to a high-energy fall failed to show any correlation to the age of the patient $(\mathrm{p}=0.8)$, whereas patients with a simple fall exhibited a pattern with a maximum frequency after the age of 74 .

Using the ASIA classification, 405 patients (37.2\%) were neurologically intact (ASIA E). The remaining 687 patients $(62.8 \%)$ had SCI secondary to spine trauma. Among them, 241 patients (22.1\%) exhibited a complete motor and sensory deficit (ASIA A), with $14.4 \%$ complete tetraplegia and $7.7 \%$ complete paraplegia. One hundred and nineteen patients (10.8\%) were ASIA B, 157 (14.3\%) ASIA C and 170 (15.6\%) ASIA D. Eight patients (0.7\%) sustained the SCIWORA type 1 and $3(0.4 \%)$ SCIWORA type 2 . Neurological evolution of spinal cord injured patients according to the ASIA is shown in Table 1.

Most of the neurological deficits occurred in response to cervical spine (upper and lower) injuries (44.2\%), followed by thoracic (36.5\%) and lumbar spine (19.3\%). Patients presenting sacrococcygeal trauma exhibited nerve root injury. The correlation between the incidence of a neurological deficit and the mechanism of injury revealed the lowest incidence of SCI for compression injuries (17.4\%), followed by distraction injuries (36.3\%). Rotational injuries were associated with the highest incidence of SCI (46.3\%), and showed the highest probability of a complete motor and sensory deficit $(\mathrm{p}=0.0017)$. The occurrence of SCI was strongly correlated to the level of injury and number of injured vertebrae $(p=0.0016)$. No correlation was found between the occurrence of the neurologic deficit, age and $\operatorname{sex}(\mathrm{p}=0.87)$.
Five hundred and twenty-three patients (47.9\%) sustained associated injuries, including head injury (10.4\%), thoracic injury (7.5\%), abdominal trauma (4.3\%), and pelvic injury $(2.1 \%)$ and orthopedic injuries (fracture of the upper or lower extremity) occurred in $23.6 \%$ patients. Among orthopedic injuries; the calcaneal fracture alone accounted for $14.2 \%$; followed by fracture of the distal radius fracture 5.4\%. Furthermore, 125 patients (11.5\%) sustained a second vertebral injury. ANOVA revealed that age, gender, injury type, number of injured vertebrae and neurological deficit significantly differed among patient who suffered from associated injuries (AI) and from those who did not (Table 2). The number of injured vertebrae was the strongest predictor for an AI, followed by a type $\mathrm{C}$ injury, male gender and occurrence of neurological deficit (Table 3). Testing the relationship between a certain injury level and the occurrence of an AI, we found that patients with injuries of the thoracolumbar junction (T11-L1) had the highest risk of suffering from an AI representing 58.2\% of all AI. For concomitant spinal injuries, $57.6 \%$ were at contiguous levels and $42.4 \%$ at noncontiguous levels. The highest incidence of AI was induced by multilevel noncontiguous spinal injuries $(89 \%)\left(\mathrm{p}=0.0016, \mathrm{Chi}^{2}=13.7\right)$. We found that most of the AI resulted from traffic accidents and highenergy falls ( $\mathrm{p}=0.0017, \mathrm{Chi}^{2}=39.9$ ).

In relation to the five anatomical segments of the spine, spinal traumas occurred most frequently in the lower cervical $(40.6 \%)$, followed by lumbar $(22.6 \%)$, thoracic $(13.4 \%)$, upper cervical $(10.8 \%)$, sacrococcygeal vertebrae $(3.9 \%)$, whereas $(8.7 \%)$ were multi-segmental injuries (Table 4). The thoracolumbar junction (T11-L2) was involved 
in 232 patients $(21.4 \%)$. The distribution of spinal injuries for each vertebra mirrored the curve with two major peaks; one at the lower cervical level and the other at thoracolumbar level. The most frequently injured vertebra was the sixth cervical vertebra in $13 \%$ followed by the first lumbar vertebra in 10\% (Figure 4).

Both operative treatment (Figure 5) and conservative treatment were employed in this cohort. Overall, the use of operative treatment $(64.8 \%)$ exceeded that of conservative treatment $(35.2 \%)$. The cure rate for lumbar spine injuries was greater that of other segments and upper cervical spine injuries had the highest ineffective treatment and mortality rates. The overall mortality rate was $7.9 \%$. Analyses of the univariate associations between spine trauma variables and mortality identified six univariate variables trending toward spine trauma mortality with statistical significance $(\mathrm{p}<0.05)$. They were upper cervical spine injuries $(\mathrm{OR}=3.2)$, motor vehicle occupants $(\mathrm{OR}=1.9)$, type $\mathrm{C}$ injuries $(\mathrm{OR}=4.1)$, multilevel injuries $(\mathrm{OR}=7.1), \mathrm{AI}(\mathrm{OR}=4.9)$, and ASIA A $(\mathrm{OR}=7.1)$. The mortality rate for male patients $(5.3 \%)$ was twice that of female patients (2.6\%). The mean follow-up time was 49 months (range, 3-158 months).

\section{Discussion}

In this study from our institution through one decade and half, we presented an overview of epidemiological features of spine traumas from occipital condyles to the coccyx among 1092 patients. This high number of spinal trauma patients reported in our series may be due to the fact that our hospital is a major trauma center for the state, and thus, an unusually high number of patients with traumatic spine injuries are flown in for treatment. However, our general cohort epidemiological findings concur with current literature. The analyses of the whole study group revealed that two-thirds of the patients were male, which was reported before $[13,18,19]$. In our context, the high male prevalence (74.3\%) is explained by more hazardous socio-economic activities in men than in women. These are masonry, manual water well drilling, mounting electrical poles, combat sport (wrestling), driving, climbing, carpentry, harvesting fruits and leaves for livestock. Over all $58.9 \%$ of people with spinal injury were between 18 and 39 year-olds (young adults). This finding is confirmed by other studies $[7,10,11,14]$.

Chiu and coauthors $[20,21]$ reviewed global epidemiological studies of traumatic SCI within 2 decades and compared differences between developed and developing countries. They found that traffic accidents (MVC) were the leading cause of injury in developing countries, whereas falls were the leading cause of injury in developed countries. In our study, MVC (55.8\%) rank higher than high falls (32.6\%). This result agrees with the finding obtained by other authors in developing country $[2,9,22,23]$. Our result also contradicted with the findings of reports from developed countries which noted that most of the injuries were as a result of a fall from a height followed by MVC $[3,12,19]$. In our study, various factors incriminated for traffic collision were the poor quality of old-fashioned roads, non-compliance with traffic safety measures and sometimes young men's risk-taking with motor vehicles. Highenergy fall-related injuries were due to deep fall for water well diggers, occupational and accidental domestic high building fall, fall from trees and defenestration. Fall-related injuries occurred predominantly at the thoracolumbar junction $(\mathrm{p}=0.001)$ because most of patients landed with either their back or buttocks, whereas lower cervical level was more common in MVC ( $\mathrm{p}=0.001)$ as victims always hit their head on glass or door.

This study revealed that complete SCI (ASIA A) were more common (22.1\%) followed by ASIA D (15.6\%), ASIA C (14.3\%) and lastly ASIA B (10.8\%). This result agrees with the findings of others authors [4,24]. This might be a result of the mechanism of the injury. Majority of the injuries occurred as results of MVC (58.5\%) and highenergy falls from a height (32.6\%) which must have caused a severe damage to spinal cord resulting in complete SCI (ASIA A). Tetraplegia (14.4\%) was more common than paraplegia (7.7\%) and this in line with previous reports [25-28]. This greater number of tetraplegic patients compared to paraplegic patients in this study might be as a result of the greater number of cervical injuries (51.4\%) with upper and lower cervical accounting for $10.8 \%$ and $40.6 \%$ respectively.

Spinal trauma is frequently associated with concomitant systemic injuries including head, intra-abdominal, thoracic injuries and longbone fractures $[8,9,29,30]$. Unlike previous reports, head and facial injuries were the least common associated injuries because patients with these injuries were respectively managed in neurosurgery and maxillofacial departments. Most of our patients who were injured in a fall from height were known to have been involved in fall from trees with primary impact on foot soles and secondary on hand palms, which may explain the high number of associated calcaneal (14.2\%) and distal radius $(5.4 \%)$ fractures.

The treatment outcome assessment indicated a high in-hospital mortality rate $(7.9 \%)$ for TSI than was found in previous studies $[2,5,16]$. We attribute this rate mostly to the medical insurance system and financial issues. However, the cost in pain, disability, social dependence and health care expenses are quite high. Most low-income people have to pay out of their own pockets because the rate of medical insurance coverage is low. There are not enough resources available to pay huge medical expenses associated with rehabilitation and a longer-term follow-up system for patients with SCI. In the present study, patients with ASIA A injuries had the highest mortality rate.

Overall, this study was able to investigate some interesting correlations that will be able to guide physicians in their initial diagnostic work up. However, the retrospective nature of our work goes along with limitations, the most obvious being the dependence upon the quality of the data recorded in the medical files. Furthermore; this study is a single-center epidemiological study. Despite treating the majority of spine trauma in our country, this study is unable to determine the nationwide incidence and prevalence of SCI and spine trauma.

\section{Conclusion}

This study provides baseline spine trauma epidemiological data. Many of the spinal injuries in this study could have been prevented, as most were a result of MVC and a fall from a height. Improved traffic safety standards, including road maintenance and protective devices (like helmets) for masons may have reduced the incidence of spinal trauma. The age distribution of patients with traumatic spine injuries revealed that the young adult group (18-39 years) is more affected (58.9\%) and this group represents the main providers of financial and social security in our environment. The study's unique feature of delineating variables with statistical significance trending toward better management provides useful data to guide future researches, benchmarking, public health policy, and efficient resource allocation for the management of spine trauma.

\section{Acknowledgment}

We acknowledge Miss Larissa Mahoro Musaninyage for her professional English editing and help with statistical analysis

\section{Conflict of Interest}

No potential conflict of interest relevant to this article was reported

\section{Ethical Approval}


Citation: Sane JC, Hope JMV, Souleymane D, Kassé AN, Diouf JD, et al. (2018) Epidemiology of Traumatic Spinal Injury: A 15-Year Retrospective Study of 1092 Cases. J Spine 7: 429. doi: 10.4172/2165-7939.1000429

This article does not contain any studies with human participants or animals performed by any of the authors.

\section{Informed Consent}

The informed consent was obtained from individual participant to this study

\section{Funding}

No benefits in any form have been received or will be received from a commercial party related directly or indirectly to the subject of this article.

\section{Author Contributions}

All 10 authors listed for this manuscript have contributed to the manuscript as follows:

1. Conception and design: All authors.

2. Administrative support: All authors.

3. Provision of study materials or patients: All authors.

4. Collection and assembly of data: All authors

5. Data analysis and interpretation: Jean Marie Vianney HOPE and Jean Claude SANE.

6. Manuscript writing: All authors.

7. Final approval of manuscript: All authors.

\section{References}

1. Kang $Y$, Ding $H$, Zhou H, Wei Z, Liu L, et al. (2018) Epidemiology of worldwide spinal cord injury: A literature review. Journal of Neurorestoratology 6: 1-9.

2. Tafida MA, Wagatsuma Y, Ma E, Mizutani T, Abe T (2017) Descriptive epidemiology of traumatic spinal injury in Japan. J Orthop Sci 30: 1-4.

3. Rahimi-Movaghar V, Sayyah MZ, Akbari H, Khorramirouz R, Rasouli MR, et al (2013) Epidemiology of traumatic spinal cord injury in developing countries: A systematic review. Neuroepidemiology 41: 65-85.

4. Van Den Heuvel M, Jansz L, Xiong X, Singhal B (2017) People with spinal cord injury in New Zealand. American Journal of Physical Medicine \& Rehabilitation 96: S96-S98.

5. Kattail D, Furlan JC, Fehlings MG (2009) Epidemiology and clinical outcomes of acute spine trauma and spinal cord injury: Experience from a specialized spine trauma center in Canada in comparison with a large national registry. $J$ Trauma 67: 936-943

6. Singh A, Tetreault L, Kalsi-Ryan S, Nouri A, Fehlings MG (2014) Global prevalence and incidence of traumatic spinal cord injury. Clin Epidemiol 6: 309-331.

7. Roche SJ, Sloane PA, McCabe JP (2008) Epidemiology of spine trauma in an Irish regional trauma unit: A 4-year study. Injury 39: 436-442.

8. Srivastava RN, Singh A, Garg RK, Agarwal A, Raj S (2015) Epidemiology of traumatic spinal cord injury: A SAARC perspective. International Journal of Molecular Biology \& Biochemistry 3: 9-22.

9. Wang H, Liu X, Zhao Y, Ou L, Zhou Y, et al. (2016) Incidence and pattern of traumatic spinal fractures and associated spinal cord injury resulting from motor vehicle collisions in China over 11 years: An observational study. Medicine 95: 43.

10. Haddadi K, Yosefzadeh F (2016) Epidemiology of traumatic spinal injury in North of Iran: A cross-sectional study. IrJNS 1: 11-14

11. Van Den Berg ME, Castellote JM, Mahillo-Fernandez I, De Pedro-Cuesta
J (2010) Incidence of spinal cord injury worldwide: A systematic review. Neuroepidemiology 34: 184-192.

12. McCaughey EJ, Purcell M, McLean AN, Fraser MH, Bewick A, et al. (2016) Changing demographics of spinal cord injury over a 20-year period: A longitudinal population-based study in Scotland. Spinal Cord 54: 270-276.

13. Tee JW, Chan CHP, Fitzgerald MCB, Liew SM, Rosenfeld JV (2013) Epidemiological trends of spine trauma: An Australian level 1 trauma center study. Global Spine J 3: 75-84.

14. Chabok SY, Safaee M, Alizadeh A, Dafchahi MA, Taghinnejadi O, et al. (2010) Epidemiology of traumatic spinal injury: A descriptive study. Acta Med Iran 48: 308-311.

15. Liu P, Yao Y, Liu MY, Fan WL, Chao R, et al. (2012) Spinal trauma in mainland china from 2001 to 2007: An epidemiological study based on a nationwide database. Spine 37: 1310-1315.

16. Wang H, Zhang Y, Xiang Q, Wang X, Li C, et al. (2012) Epidemiology of traumatic spinal fractures: Experience from medical university-affiliated hospitals in Chongqing, China, 2001-2010. J Neurosurg Spine 17: 459-468.

17. Argenson C, De Peretti F, Eude P, Lovet J, Hovorka I (1997) Classification of lower cervical spine injuries. Eur J Orthop Surg Traumatol 7: 215-229.

18. Magerl F, Aebi M, Gertzbein SD, Harms J, Nazarian S (1994) A comprehensive classification of thoracic and lumbar injuries. Eur Spine J 3: 184-201.

19. Leucht P, Fischer K, Muhr G, Mueller EJ (2009) Epidemiology of traumatic spine fractures. Injury 40: 166-172.

20. Oliver M, Inaba K, Tang A, Branco BC, Barmparas G, et al. (2012) The changing epidemiology of spinal trauma: A 13-year review from a Level I. Injury 43: 12961300.

21. Chiu WT, Lin HC, Lam C, Chu SF, Chiang YH, et al. (2010) Review paper: Epidemiology of traumatic spinal cord injury: Comparisons between developed and developing countries. Asia Pac J Public Health 22: 9-18.

22. Ibikunle O, Okoro EO (2018) A fifteen years retrospective study of spinal cord injury in South-Eastern Nigeria. EC Orthopaedics 9: 671-687.

23. Sothmann J, Stander J, Kruger N, Dunn R (2015) Epidemiology of acute spinal cord injuries in the Groote Schuur Hospital Acute Spinal Cord Injury (GSH ASCI) Unit, Cape Town, South Africa, over the past 11 years. S Afr Med J 105: 835-839.

24. Obalum DC, Giwa SO, Adekoya-Cole TO, Enweluzo GO (2009) Profile of spinal injuries in Lagos, Nigeria. Spinal Cord 47: 134-137.

25. Draulans N, Kiekens C, Roels E, Peers K (2011) Etiology of spinal cord injuries in Sub-Saharan Africa. Spinal Cord 49: 1148-1154

26. Fisher CG, Noonan VK, Dvorak MF (2006) Changing face of spine trauma care in North America. Spine 31: S2-S8.

27. Jackson AB, Dijkers M, DeVivo M, Poczatek RB (2004) A demographic profile of new traumatic spinal cord injuries: Change and stability over 30 years. Arch Phys Med Rehabil 85: 1740-1748.

28. Kawu AA (2012) Pattern and presentation of spine trauma in Gwagwalada-Abuja Nigeria. Niger J Clin Pract 15: 38-41.

29. Chu D, Lee YH, Lin CH, Chou P, Yang NP (2009) Prevalence of associated injuries of spinal trauma and their effect on medical utilization among hospitalized adult subjects: A nationwide data-based study. BMC Health Serv Res 9: 137.

30. Luna LM, Mendoza RJA, Oropeza YM (2017) Epidemiology of spine trauma in patients with polytrauma. Coluna/Columna 16: 121-126. 